\title{
Role of Cultural Dimensions in Safety Performance of Global Oil and Gas Industry
}

\author{
Suparna Gharpurea ${ }^{1}$, Sandip Roya ${ }^{1}$, Pooja Purang ${ }^{2 *}$ and Surajit Bhattacharyya ${ }^{2}$ \\ ${ }^{1}$ Department of Chemical Engineering, Indian Institute of Technology Bombay, India \\ ${ }^{2}$ Department of Humanities and Social Sciences, Indian Institute of Technology Bombay, India
}

Submission: December 19, 2017; Published: April 13, 2018

*Corresponding author: Pooja Purang, Department of Humanities and Social Sciences, Indian Institute of Technology Bombay, Mumbai 400076, India, Email: purangp@iitb.ac.in

\begin{abstract}
Increasingly stringent regulations that have prompted improved process safety management programs have had a positive effect on safety performance, as reflected in decreasing global human loss metrics. However, human and organizational factors continue to remain significant causes of losses. Several studies reported in the literature have established that socio-cultural factors can influence employee behavior, ᄀand therefore safety performance. This study explores the possible influence of such cultural factors on the safety performance of global oil and gas industry. Hofstede's [1] national culture framework is used as a basis for quantifying cultural attributes. The framework is comprised of five dimensions, namely power distance, individualism, masculinity, uncertainty avoidance, and long-term orientation. A set of hypotheses on the probable nature of effect of each of these cultural dimensions on safety performance in the global oil and gas industry are postulated. Using lost time injury frequency (LTIF) data-a safety performance indicator-available at the country-level from the International Association of Oil \& Gas Producers (OGP) as the dependent variable, a negative binomial model is estimated with the Hofstede's dimensions as explanatory variables. The analysis shows that high power distance, low individualism, low uncertainty avoidance, and high long-term orientation improve safety performance. The dimension of masculinity, however, appears to have no significant effect on human losses. The findings suggest that as in other industry sectors studied by other researchers, national cultural factors are likely to underlie and hence determine safety performance in the global oil and gas industry as well.
\end{abstract}

Keyword: Hofstede's cultural dimensions; Oil and gas industry; Safety performance; Loss time injury frequency

\section{Introduction}

This study examines the possible relationship between national culture value orientations and organizational safety culture in high risk industries such as aviation, shipping, construction, and chemicals. In the present work, we explore the existence of cultural determinants to the safety performance of global oil and gas industry. The chemical industry as a whole is part of the so-called "high reliability" industries, which are characterized by an elevated concern for safety, as a single catastrophe can result insignificantly large human and/or collateral losses. Substantial resources by way of time and capital are therefore, invested to ensure that hazards are controlled and potential losses minimized. Over the preceding decades, several regulations have also been promulgated across the world to promote pro-active process safety management. Examples include various guidelines from the Occupational Safety and Health Administration (OSHA) of the US Department of Labor and the PSM regulation, (OSHA, 1992), and the Seveso Directives by the European Union [2]. These guidelines and directives specify a set of minimum requirements pertaining to hazard management that must be met by manufacturers.

Increasing stringency of safety regulations has compelled organizations to effect continuous pro-active improvements in safety management programs. It is possible that this could be exerting a positive influence on safety performance, as evident, for example, from the decreasing trend of loss metric [3] of the global oil and gas industry. However, while installations have become technically superior and safer than their predecessors, human and organizational factors have emerged as key areas of concern for ensuring safe operation of hazardous plants [4]. Very recently, Kidam and Hurme [5] have analyzed accidents reported in the Failure Knowledge Database (www.sozogaku.com/fkd/ en/) from Japan and reported that "human and organizational factors" constitute the largest single contributor to process accidents, at a level of around $20 \%$. Indeed over the recent decade organizational factors have received considerable attention as probable latent, causative agents behind large scale accidents 
[6]. There have also been attempts to link organizational factors (training, experience, procedures, management commitment, leadership, safety climate, etc.) to employee safety behavior and losses [7-9] and organizational factors have been demonstrated to be valuable measures of organizational safety [10]. For example, even if an organization may advocate good return-towork and post-injury management policies and good worker safety training, safety performance might be substantially reduced without strong management commitment to safety [9]. In general, organizational factors may be influenced by various external factors such as socio-economic status of the country, the level of technological development and national culture [4]. Thus, organizational factors may be country-specific and their effect on safety performance may vary from country to another.

A sound safety culture embodies behaviors that are beneficial for safety. Typical behavior modification programs like Behavior-based safety [11], tend to focus on observing and modifying workplace behaviors by providing incentives; however, this approach does not accord adequate emphasis to more fundamental, cultural determinants of such behavior.

A considerable amount of research has been reported over the recent years which aim at establishing relationships between national culture and safety, particularly in high reliability industries like aviation, shipping, construction, and chemicals [4,12-15]. Merrit's [12] study involving male pilots around the world found that cultural influences on behavior were prevalent in the commercial aviation industry. The study concluded that ".. even in a highly specialized, regulated profession such as aviation national culture still exerts a meaningful influence on attitudes and behaviors over and above the occupational context". It was argued that pilot training, therefore, needs to take into account cultural differences. It was also concluded that national cultural attributes may underlie and interact with other socio-economic factors to determine safety performance. The study by Havold [13] examined the effect of national culture on safety orientation of seafarers, and concluded that national culture was associated to organizational safety culture in this occupational context as well. Lu et al. [15] studied the work habits of seafarers from China, Taiwan, and the Philippines, and concluded that national culture is one of the important determinants of human failures, and that certain aspects of national culture are related to certain kinds of human failures. These studies, therefore, underscore the need to understand the nature of influence of national culture on workplace behavior in general.

Since earlier studies have established national culture as a causal factor in aviation safety, it may be reasonable to expect that such influence may be inherent to other high risk, high technology industries as well. In general, culture effects are expected to arise where organizational agents apply culturally induced knowledge in making organizational decisions or choice of practices [16]. Hence, interpersonal factors like power and authority structures, communication and delegation, all aspects that impact safety performance can be guided by cultural factors. The present study thus has been carried out to explore the possible role of national cultural dimensions on the safety performance of the global oil and gas industry, a technology sector characterized by relatively high risk levels and prone to substantial losses each year Bergh et.al. [17]. The study is expected to fill a gap in the current literature and also serve to further delineate the possible role of national culture in workplace safety. An additional, practical goal of such research is to formulate behavior modification strategies consistent with observed specific cultural dependencies, which would contribute to improved safety performance in the technology sector.

This study uses Hofstede's framework of national cultures, one of the most widely used classification of value orientations across nations that have applications in cross-cultural research [18]. We explore the effect of value orientations [1] namely, power distance, individualism, masculinity, uncertainty avoidance, and long-term orientation on safety performance as measured by the "lost time injury frequency" (LTIF) metric (= number of lost work day cases and fatalities per million hours worked) for the global oil and gas industry, The findings show that power distance, individualism, uncertainty avoidance and long term orientation are likely determinants to the safety performance in this technology sector. The results obtained from the regression analysis are discussed in terms of potential impact of each dimension on workplace behavior.

In the following section the various national cultural dimensions and their probable impact on workplace safety behavior are discussed. This is followed by the elucidation of the research methodology and the results. In conclusion, findings are summarized and recommendations for improvements through further studies are suggested.

\section{Cultural Dimensions and Safety Behavior}

As has already been mentioned in the foregoing section, the Hofstede cultural dimensions considered in the present study are: power distance, individualism, masculinity, uncertainty avoidance, and long-term orientation. In this section relevant literature that demonstrates the influence of cultural dimensions on safety behavior and performance in the workplace has been discussed and hypothesis developed. The strength of the hypotheses are subsequently examined through the quantitative nature of correlation and regression analysis among the cultural dimensions and the loss metric LTIF for the global oil and gas industry.

\section{Power distance}

Power distance (PDI) is defined as "the extent to which the less powerful members of organizations and institutions accept and expect that power is distributed unequally" [1]. High PDI cultures tend to discourage "speaking up", interference that challenges authority, and confrontational behavior [19]. High PDI can thus hinder pertinent, two-way communication as it 
can potentially lead to conflict between members from different organizational hierarchies (Hofstede, 1980). High PDI cultures, thus, tend to be relatively authoritarian and individuals are less likely to deviate from rules imposed on them (Hofstede, 1980; [20]. Indeed, PDI has been shown to correlate positively with a propensity towards acquiescence (Smith [21], Johnson, et al. [22]. Thus while on one hand, high PDI adversely impacts free communication, on the other hand reduces the likelihood of non-compliance. Both open communications and compliance on the part of frontline workers with operating procedures and rules is critical for plant safety [23-25]. Therefore, the present researchers propose that the net effect of power distance on safety performance is likely to be positive. Hypothesis 1: Power distance improves safety performance.

\section{Individualism}

As described by Hofstede [20] individualism (IDV) is a characteristic of a society in which everyone is expected to look after him/herself and her/his immediate family only.Collectivism, on the other hand, describes a society in which people are integrated into strong, cohesive groups, which throughout their lifetime continue to protect them in exchange forum questioning loyalty. Although considered an independent societal trait IDV is significantly correlated to PDI, with persons from high PDI cultures being more collectivistic in nature (Hofstede, 1991, [20]. In general, collectivism fosters cooperative communication, conformance, and obedience $[26,20]$. Collectivist cultures, thus, encourage compliance with rules that benefit the collective, concern for colleagues, and a preference to group goals over that of the individual. Based on the foregoing observations, it may be reasonable to expect that a collectivist human trait would exert a positive influence on safety performance. This may be framed as a hypothesis in the following manner. Hypothesis 2: Individualism affects safety performance negatively.

\section{Masculinity}

Cultural masculinity (MAS) stands for a focus on ego and material gains; while cultural femininity emphasizes focus on relationships, people, and quality of life [27]. Further, masculinity impacts people's motivations, making competitiveness a preferred attribute, while increasing risk appetite [28]. Highly masculine cultures, thus, tend to place a low value on cooperation and caring for others - success in one's chosen career and competition being more important [15]. These beliefs further lead to attitudes that reflect enhanced self belief and confidence in one's ideas and actions. The net effect of such traits on safety behavior may be difficult to ascertain. However, as demonstrated by Lu et al. [15], low masculinity appears to be more conducive to safe behavior. In certain contexts excessive confidence has been suggested to be responsible for a decreased sense of vulnerability, leading to weakening of alertness to safety-deviant behavior. Such factors may have contributed to major disasters such as the Challenger and Columbia accidents $[29,30]$. Hypothesis 3: Masculinity affects safety performance egatively.

\section{Uncertainty avoidance}

Uncertainty avoidance (UAI) indicates "a society's tolerance for uncertainty and ambiguity" [1]. Members of cultures that rank high on UAI are uncomfortable in the face of potentially unforeseen outcomes in the future and take efforts to minimize the likelihood of the same. People from such cultures, thus, encourage creation of rules and regulations so as to minimize ambiguity [15]. In contrast, people from low UAI cultures are more open to uncertain situations, and rely on their own outlook to determine a course of action [31]. Since high UAI is likely to induce the creation and subsequent compliance with rules and regulations, high UAI is expected to be conducive to lowering of losses. Hypothesis 4: Uncertainty avoidance affects safety performance positively.

\section{Long-term orientation}

Long-term orientation (LTO) is associated with the values of perseverance and thrift, and an outlook orientation towards the future. On the contrary short term orientation, is associated with values like respect for tradition, saving face, and fulfilling social obligations [28] and is oriented more towards the past and the present. Hofstede et al. [32] associate LTO with a focus on "profits 10 years from now", as opposed to this year's profits. Furthermore, LTO corresponds to work values like self-discipline, accountability, and learning. Cultures with relatively short-term orientation may feature potential conflicts between managers' and workers' aspirations and goals. While some studies $[13,14]$ have found no significant correlation between LTO and safety, Lu et. al. [15], have reported that LTO can even contribute to an increase in human failures. Moreover, they find that this cultural dimension may play a moderating role on the impact of the other dimensions on human failures. Therefore, some manifestations of LTO seem to be beneficial for safety, while others seem to be unfavorable. One may, however, argue that in general LTO is likely to promote planning ahead, compliance, and discipline among workers and management, and these traits are expected to reinforce safe behavior; the researchers therefore hypothesize that it is likely to be beneficial for process safety management. Hypothesis 5: Long-term orientation positively affects safety performance.

\section{Research Methodology}

This study focused on safety performance in global oil and gas industry as this sector is characterized by high risks and substantial losses in case of accidents. This sector reported the highest average value of insurance claim over 2009-2013 accident years at about $€ 20.8$ million per claim, followed by aviation for which average claim value was $€ 5.27$ million [33]. The review records various structural factors in way of contextualizing the loss trend. However, the observed trend also underscores the need for a fundamental analysis of the root causes of the losses endured by the oil and gas sector.

In line with the foregoing observation, quantitative measures of country level loss data for the oil and gas industry for the 
period 2008-2012 are considered in the present study. The analysis comprised of regressing the measure of loss data on the representative national scores on selected cultural dimensions.

The variables used to test the hypotheses 1-5 advanced in the foregoing section are: power distance (PDI), individualism (IDV), masculinity (MAS), uncertainty avoidance (UAI) and long-term orientation (LTO). In quantitative terms, the scores of these cultural dimensions as assigned to various nations by the Hofstede centre, were used as explanatory variables. These were obtained from the online source: geert-hofstede.com

The dependent variable is the Lost Time Injury Frequency (LTIF) for the oil and gas industries of 28countries. LTIF is one of the common metrics of safety performance and is defined as "the number of lost time injuries (fatalities + lost work day cases) incidents per 1,000,000 hours worked" [3]. Further, Lost Work Day Case (LWDC), is defined as "any work related injury other than a fatal injury which results in a person being unfit for work on any day after the day of occurrence of the occupational injury". "Any day" includes rest days, weekend days, leave days, public holidays or days after ceasing employment".

Member companies of the OGP from each country report their losses to the body, which are then consolidated into country-level metrics. In the present work, the LTIF metric data was derived from annual OGP Safety Performance Indicators reports for the years 2012 to 2008 (ibid.). Specifically, LTIF values for 28 countries in the sample were averaged over 5 years of available data (2008-2012). This was done to obtain a more reliable indication of safety performance of each country, and also to limit a skewing of data caused by outliers.

LWDC is an example of "count data", ie, it can only assume non-negative integer values; while LTIF is LWDC normalized using the number of man-hours worked. Since Poisson and Negative Binomial regression models are appropriate for analysis of count data [34], a reformulated dependent variable, LTIFR-the integer form of LTIF (LTIF multiplied by 100) has been used.

\section{Analysis}

Pairwise correlations and tests of multicollinearity: Pairwise correlations between all variables were first obtained using the software Stata 10This was done to ascertain any multicollinearity that may exist between the variables, and to eliminate the possibility of such pairs being included simultaneously as regressors in the same model. Two commonly employed tests for multicollinearity have been carried out: calculation of the Variance Inflation Factor (VIF) and the Condition Number (CN), [35]. While a clear threshold value of VIF above which existence of multicollinearity between variables may be assumed is not available, a value of 15 or more for condition number is indicative of multicollinearity. In the present work, wherever tests have suggested probable multicollinearity between the binary variable pairs, they have been subsequently employed in separate regression models.

Table 1: Pairwise correlations.

\begin{tabular}{|c|c|c|c|c|c|}
\hline & PDI & IDV & MAS & UAI & \\
\hline PDI & 1 & & & & \\
\hline IDV & $-0.7044^{*}$ & 1 & 1 & 1 & \\
\hline MAS & 0.174 & -0.0844 & 0.279 & -0.0019 & 1 \\
\hline UAI & 0.1511 & -0.0754 & -0.0286 & 0.2086 & $-0.3306^{*}$ \\
\hline LTO & 0.1348 & -0.0727 & -0.0348 & & \\
\hline LTIFR & $-0.4294^{*}$ & $0.3756^{*}$ & & & \\
\hline
\end{tabular}

Correlation analysis shows that two independent variables PDI and IDV are negatively correlated to each other and PDI and LTO are positively correlated with LTIFR, while IDV negatively correlates with LTIFR. The results of the correlation analysis are given in Table 1.

In particular, the VIF and the CN between PDI and IDV were found to be 1.98 and 12.9 respectively. The closeness of the $\mathrm{CN}$ to the threshold value $(\sim 15)$ is suggestive of possible multicollinearity; therefore, PDI and IDV are included independently in separate regression models.

\section{Regression}

In the present case the mean value of LTIFR is 75.3 whereas the variance is 2823.7. This implies that the distribution is overdispersed, the appropriate regression model in such cases being the Negative Binomial model [34]. The form of the Negative
Binomial regression model is given by eqn.1, where $\mathrm{Y}$ is the dependent variable and $\mathrm{Xi}$ denotes independent variables, and $\beta_{i}$ are the corresponding coefficients; $\beta_{0}$ while is a constant and is the prediction error (residual).

$$
\ln Y=\beta_{0}+\sum_{i=1}^{n} \beta_{i} X_{i}+\varepsilon
$$

This can be alternatively written as

$$
Y=\exp \left[\beta_{0}+\sum_{i=1}^{n} \beta_{i} X_{i}\right]+\varepsilon
$$

The coefficients of the above equation may be understood more conveniently using "incidence rate ratios" (IRR). The IRR is interpreted as follows: when an explanatory variable for example, PDI - increases by 1.0 unit, all other explanatory 
variables remaining constant, LTIF $_{\mathrm{R}}$ needs to be multiplied by the corresponding $I_{R R_{P D I}}$ to obtain its new value. For a general explanatory variable $\mathrm{X}_{\mathrm{i}}$, the IRR is given by:

$$
I R R_{X_{i}}=\exp \left[\beta_{i}\right]
$$

It follows that a large value of IRR indicates that the explanatory variable is an important determinant of the dependent variable.

Two regression models were run. As PDI and IDV show significant correlation they have been considered separately in two models. The software Stata 10 was used to conduct the regression analyses. Once a first level regression was carried out, explanatory variables for which the coefficients were found to be insignificant were removed, and the regression equation with the remaining variables re-estimated.

\section{Results and Discussion}

The coefficients of the explanatory variables obtained from the regression analysis for the models 1 and 2 are summarized in Table 2. As is evident, the coefficient of MAS is relatively insignificant in both the models. Thus, both models were revised by eliminating MAS from the corresponding sets of explanatory variables, and the regression redone in order to test if the model fit was enhanced.

Table 2: Regression coefficients for explanatory variables in Models 1 and 2.

\begin{tabular}{|c|c|c|c|c|}
\hline \multirow[b]{3}{*}{ Variable $\left(X_{i}\right)$} & \multicolumn{2}{|c|}{ Model 1} & \multicolumn{2}{|c|}{ Model 2} \\
\hline & \multicolumn{2}{|c|}{$\begin{array}{l}\text { Pseudo } R^{2}=0.048 \\
p>\chi^{2}=0.007(d f=3)\end{array}$} & \multicolumn{2}{|c|}{$\begin{array}{l}\text { Pseudo } R^{2}=0.049 \\
p>\chi^{2}=0.007(d f=3)\end{array}$} \\
\hline & Coefficient $\left(\beta_{i}\right)$ & $P>|z|$ & Coefficient $\left(\boldsymbol{\beta}_{\mathrm{i}}\right)$ & $P>|z|$ \\
\hline PDI & -0.018 & 0.001 & - & - \\
\hline IDV & - & - & 0.016 & 0.001 \\
\hline MAS & -0.000 & 0.958 & -0.001 & 0.833 \\
\hline UAI & 0.013 & 0.01 & 0.012 & 0.024 \\
\hline LTO & -0.011 & 0.04 & -0.013 & 0.011 \\
\hline Constant $\left(\beta_{0}\right)$ & 5.030 & 0 & 3.460 & 0 \\
\hline
\end{tabular}

According to hypothesis 1, higher PDI may lead to better safety performance. Thus, higher PDI is expected to reduce the loss metric, LTIFR. This is supported by the significant value of the regression coefficient for PDI in Model $1(\beta=-0.018, p=$ 0.001). As discussed earlier, PDI is expected to have a complex, and even conflicting influence on safety-related behavior. It can hamper two-way communication between different hierarchies in an organization because of unwillingness on employees' part to question decisions made by their superiors (Hofstede, 1980). Indeed, individuals from high PDI cultures tend to depend on indirect hints and non-verbal cues for communication [20]. Individuals from such cultures are also likely to value obedience, and, therefore would be more compliant to the instructions and procedures Merkin [35]. Given that such individuals are more likely to comply with stated rules and guidelines, higher PDI could result in lesser injuries and fatalities at the workplace, and hence a lower LTIF. The regression result, therefore, affirms hypothesis 1 .

The second hypothesis proposes that IDV is likely to impact safety performance negatively. In other words, higher degree of individualism may act as a significant causal factor behind higher losses, which may translate to a positive contribution to or enhancement in LTIFR. The significant regression coefficient for IDV in Model 2 ( $\beta=0.016, p=0.001)$, supports the hypothesis. As has been pointed out earlier, persons from a collectivistic society are likely to align their personal standards with their group's benchmarks $[15,36]$; that is, they are less likely to deviate from behaviors most conducive to their group's wellbeing, and follow directions of superiors Tarfarodi et al. [37]. Therefore, with a higher degree of interest for collective benefits, persons from collectivist cultures are expected to be relatively more compliant with compulsory safety performance requirements [38]. It follows, therefore, greater emphasis on individual benefits over group benefits is likely to affect safety performance negatively.

According to hypothesis 3 , higher masculinity (MAS) is likely to be unfavorable for higher safety performance, and, therefore may lead to increase in LTIFR. However, in both models 1 and 2 , the regression coefficients are found to be insignificant $(\beta=-$ $0.000, p=0.958$ and $\beta=0.001, p=0.833$, respectively). Given that this dimension has been found to negatively affect work safety [15]; Tice and Baumeister, 2004; [13] its seeming lack of influence vis-à-vis the loss profile of the global oil and gas industry is somewhat unexpected. It is possible that some of the impact of MAS is neutralized by process safety management systems, which aim to lower risk propensity through careful planning; hence the effect of MAS on LTIFR is not apparent. However, the present authors feel the need to examine the effects of MAS on safety performance through various mediators.

According to hypothesis 4, UAI is expected to enhance safety performance and therefore enable lower losses, i.e, a decrease in LTIFR. However, significant positive regressions obtained through both the models 1 or $2(\beta=0.013, p=0.01$ and $\beta=0.012$, 
$\mathrm{p}=0.024$ respectively) do not appear to support this hypothesis. These findings suggest that higher UAI correlates with increased LTIF. It appears difficult to find an unambiguous resolution of this question by recourse to the associated literature. For example, Lu et. al. [15] reports no significant relationship between uncertainty avoidance and human failures. However, it may be argued that high uncertainty avoidance cultures are expected to provide for clearer and comprehensive safety guidelines which, therefore, should impact safety performance positively. However, it is also be plausible that high uncertainty avoidance may confer rigidity to responsiveness of people to critical situations, as the decision-making environment may be too highly structured. Indeed, findings by Burke et. al. [39] imply that high uncertainty avoidance could reduce the effectiveness of safety training as far as reducing accidents is concerned. Therefore, as with the case of MAS, the relationship of this value orientation to losses also warrants further study to conclusively determine the probable nature of its impact. Hypothesis 5 proposes that LTO is likely to augment safety performance which, in effect, would translate to lower losses, i.e., LTIFR. The regression coefficients of the models 1 and $2(\beta=-0.011, p=0.04$ and $\beta=-0.013, p=0.011$ respectively), support the hypothesis. As described earlier, long-term orientation, promotes behaviors that prioritize "profits 10 years from now" [32], as opposed to immediate gains. It is, therefore, to be expected that this cultural dimension would enhance safety performance as focus on ensuring long term viability of the organization would bring emphasis on planning, timely addressing of issues, attention to safety procedures and processes etc. As observed earlier, on analysis of the Failure Knowledge Database from Japan [5] have reported that "human and organizational factors" may be directly linked to about $20 \%$ of the accidents. The rest $80 \%$ include contributors that are considerably varied and do not have human origin in an immediate sense; they include mechanical, electrical, operational and other hazard sources. Thus, the statistical significance of $\beta 0$ in equations 1 and 2 is that it may account for such miscellaneous determinants beyond direct human factors, in a lumped manner.

The foregoing discussions in this section, thus, highlight the complex influences exerted by national culture dimensions on safety performance. While regressions show significant influences of PDI, IDV and LTO dimensions, effects of MAS and UAI appear contradictory to present literature. It may be noted that while national cultural dimensions may remain the "origin" of behaviour and motivations of people, in an organizational environment they must necessarily be expressed through more immediate constructs such as organizational and/or safety culture. Therefore, for deeper understanding of the effects of national culture, the role of mediators like organizational and safety culture, process safety guidelines etc., need to be explored. Thus, a more comprehensive model that posits linkages between underlying national culture dimensions on the one hand and organizational and safety culture on the other appears necessary.
It is only by studying such linkages simultaneously can one explain the specific effects of national culture dimensions on workplace safety performance in wholesome manner.

\section{Conclusion}

While increasing stringency of safety regulations have been prompting organizations globally to invest in safety improvement measures and systems, human and organizational factors continue to be key contributors to process losses. Practical behavior-based safety programs that focus on positive reinforcement of desirable behavior are relatively deficient in that they do not accord adequate attention to the fundamental, cultural determinants of human behavior and error. The effects of underlying cultural attributes of people on organizational culture, behavior, and resultant safety performance have been demonstrated in various industry sectors. The present work has explored the possible existence of such effects in the oil and gas vertical of the global chemical industry. Hypotheses have been generated following a review of literature, and tested using loss data sourced from the reports of International Association of Oil and Gas Producers, and scores for each of Hofstede's national culture dimensions. Four aspects of national culture are found to have a significant impact on the safety performance metric LTIFR. Power distance, long term orientation and individualism were found to have significant effects on safety performance but not uncertainty avoidance. Thus it can be concluded that like other industries such as aviation and shipping, national culture appears to influence safety performance in the oil and gas industry as well. The power and authority structures, long term or short term goal orientation and compliance with rules and goals benefitting the collective are issues where employees apply their culturally induced knowledge. Hence national culture shapes employee decisions and choice of practices, which is critical for safety related behavior in the workplace.

While the present study focused on deriving direct correlation between national cultural factors on safety performance, 'abstract' cultural fundamentals may only manifest through a relatively more recognized attribute of organizational safety culture. Establishing a clear pathway of such influences, however, remains a challenge. The influence of national cultural value orientations on safety culture and as a result, on human behavior, is complex, interplaying with other factors such as: prevailing socioeconomic, political and regulatory environment of a nation, perhaps even its historical background, and personnel education and training levels. While the present work has been premised on gross loss data, a cross-sectional study on possible linkages between other socio-economic variables as well other process safety indicators on the one hand and employee attitudes towards safety on the other, would help understand this complex relationship more clearly. The practical objective that may be served by such explorations is that rules and policies in modern safety management systems can be tailored to incorporate effects of national culture so as to 
leverage behaviors that employees are already "conditioned" to exhibit.

\section{References}

1. Hofstede G (1994) The business of international business is culture. International Business Review 3(1): 1-14.

2. Wood MH, Fabbri L, Struckl M (2008) Writing Seveso II safety reports: New EU guidance reflecting 5 years' experience with the Directive. J Hazard Mater 157(2-3): 230-236.

3. OGP (2013) Safety Performance Indicators - 2012 Data. OGP Data Series Report No. 2012s.

4. Helmreich RL, Merrit AC (1998) Culture at Work in Aviation and Medicine: National, Organizational and Professional Influences. Gower Technical Services, Inc. Columbus, Ohio, USA.

5. Kidam K, Hurme M (2013) Statistical Analysis of Contributors to Chemical Process Accidents. Chemical Engineering Technology 36(1): 167-176.

6. Pidgeon N, O’Leary M (2000) Man-made disasters: why technology and organizations fail. Safety Science 34(1-3): 15-30.

7. Oliver A, Cheyne A, Tomas JM, Cox S (2002) The effects of organizational and individual factors on occupational accidents. Journal of Occupational and Organizational Psychology 75(4): 473-488.

8. Seo DC (2005) An explicative model of unsafe work behavior. Safety Science 43(3): 187-211.

9. Hunag YH, Ho M, Smith GS, Chen PY (2006) Safety climate and self reported injury: assessing the mediating role of employee safety control. Accident Analysis and Prevention 38(3): 425-433.

10. Takano K, Kojima M, Hasegawa N, Hirose A (2001) Interrelationships between organizational factors and major safety indicators: a preliminary field study. In: Wilpert B, Itoigawa N (Eds.), Safety Culture in Nuclear Power Operations. Taylor \& Francis, London, pp. 189-205.

11. Geller ES (2005) Behavior-based safety and occupational risk management. Behav Modif 29(3): 539-561.

12. Merrit A (2000) Culture in the cockpit: do Hofstede's dimensions replicate? J Cross Cult Psychol 31(3): 283-301.

13. Havold JI (2007) National cultures and safety orientation: A study of seafarers working for Norwegian shipping companies. Work \& Stress: An International Journal of Work, Health \&Organizations 21(2): 173195.

14. Mearns K, Yule S (2009) The role of national culture in determining safety performance: Challenges for the global oil and gas industry. Safety Science 47(6): 777-785.

15. Lu CS, Lai K, Lun YHV, Cheng TCE (2012) Effects of national culture on human failures in container shipping: The moderating role of Confucian dynamism. Accid Anal Prev 49: 457- 469.

16. Gardner HK, Earley PC (2008) Cross-cultural issues in organizational behavior. In: Barling J, Cooper CL (Eds.), The Sage Handbook of Organizational Behavior, London, California, New Delhi, Sage Publications, Singapore 1: 561-582.

17. Bergh LIV, Hinna S, Leka S, Jain A (2014) Developing a performance indicator for psychosocial risk in the oil and gas industry. Safety Science 62: 98-106.

18. Yeganesh H, Zhan Su, Sauers D (2009) The applicability of widely employed frameworks in cross-cultural management research. Journal of Academic Research in Economics 1(1): 1-24.

19. Westwood RI, Tang SF, Kirkbride PS (1991) Chinese conflict preferences and negotiating behaviour: Cultural and psychological influences. Organization Studies 12(3): 365-386.
20. Hofstede G (2001) Culture's consequences: Comparing values, behaviors, institutions, and organizations across nations. In: ( $\left.2^{\text {nd }} e d n\right)$, Sage Publications, Thousand Oaks, California, USA, pp. 79-123.

21. Smith PB (2004) Acquiescent response bias as an aspect of cultural communication style. Journal of Cross-Cultural Psychology 35(1): 5061.

22. Johnson T, Kulesa P, Cho Y, Shavitt S (2005) The relation between culture and response styles: Evidence from 19 countries. Journal of Cross-Cultural Psychology 36(2): 264-277.

23. Reason J (1998) Achieving a safe culture: theory and practice. Work \& Stress 12(3): 293-306.

24. Guldenmund FW (2000) The nature of safety culture: a review of theory and research. Safety Science 34(1-3): 215- 257.

25. Hopkins A (2011) Risk-management and rule-compliance: Decisionmaking in hazardous industries. Safety Science 49(2): 110-120.

26. Offermann LR, Hellmann PS (1997) Culture's consequences for leadership behavior: National values in action. Journal of Cross-Cultural Psychology 28(3): 342-351.

27. Hofstede G, McCrae RR (2004) Personality and culture revisited: linking traits and dimensions of culture. Cross-Cultural Research 38(1): 52-88

28. Hofstede G, Bond MH (1988) The Confucius Connection: From Cultural Roots To Economic Growth. Organizational Dynamics 16(4): 5-21.

29. CCPS (2005a) Building Process Safety Culture: Tools to Enhance Process Safety Performance, Challenger Accident Analysis, Process Safety Culture Toolkit, AICHE, New York, USA.

30. CCPS (2005b) Building Process Safety Culture: Tools to Enhance Process Safety Performance. Columbia Accident Analysis. Process Safety Culture Toolkit, AICHE, New York, New York, USA.

31. Bird A (2000) The impact of a national culture on collaboration in Proceedings of Symposium on Collaboration Across Professional Boundaries: From Education to Practice, Illinois Institute of Technology, Chicago, Illinois, USA.

32. Hofstede G, Hofstede GJ, Minkov M (2010) Cultures and Organizations: Software of the Mind. McGraw Hill, New York, USA.

33. http://www.agcs.allianz.com/about-us/news/top-causes-of-loss-forbusinesses-2014

34. Cameron A, Trivedi P (1998) Regression Analysis of Count Data. In: (1 $1^{\text {st }}$ edn), Cambridge University Press, New York, USA, pp. 61.

35. Kuh BDA, Welsch RE (2004) Regression Diagnostics: Identifying Influential Data and Sources of Collinearity. John Wiley and Sons, Hoboken, New Jersey, USA.

36. Merkin R (2006) Power distance and facework strategies. Journal of Intercultural Communication Research 35(2): 139- 160.

37. Tafarodi RW, Lang JW, Smith AJ (1999) Self-esteem and the cultural trade off: evidence for the role of individualism-collectivism. Journal of Cross-Cultural Psychology 30(5): 620-640.

38. Chow CW, Lindquist TM, Wu A (2001) National culture and the implementation of high-stretch performance standards: an exploratory study. Behavioral Research in Accounting 13(1): 85-109.

39. Burke MJ, Chan-Serafin S, Salvador R, Smith A, Sarpy SA, et al. (2007) The role of national culture and organizational climate in safety training effectiveness. European Journal of Work and Organizational Psychology (January) 16: 1-20. 
(C) This work is licensed under Creative

BY DOI: 10.19080/RAPSCI.2018.05.555653

\section{Your next submission with Juniper Publishers} will reach you the below assets

- Quality Editorial service

- Swift Peer Review

- Reprints availability

- E-prints Service

- Manuscript Podcast for convenient understanding

- Global attainment for your research

- Manuscript accessibility in different formats

( Pdf, E-pub, Full Text, Audio)

- Unceasing customer service

Track the below URL for one-step submission https://juniperpublishers.com/online-submission.php 